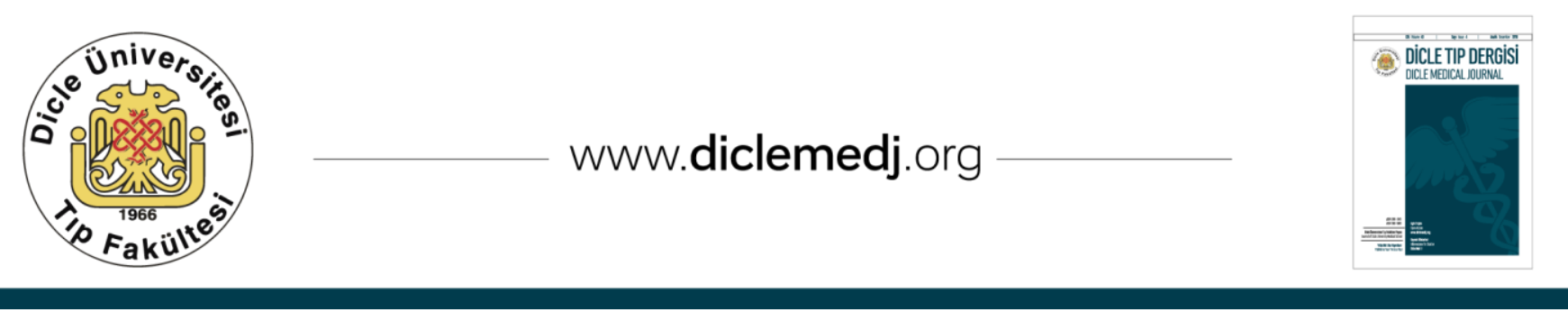

\title{
Multidisipliner Teletıp Uygulaması: Cerrahi Öncesi Telecerrahi Tanılarının Histopatoloji İle Karşılaştırılması
}

\author{
Ümran Muslu1 ${ }^{1}$ Emre Demir², Hakan Kör ${ }^{3}$, Engin Şenel ${ }^{4}$ \\ 1 Hitit Üniversitesi, Tıp Fakültesi, Plastik Rekonstrüktif ve Estetik Cerrahi Anabilim Dall, Corum, Türkiye ORCID: 0000-0003-0403-7217 \\ 2 Hitit Üniversitesi, Tıp Fakültesi, Biyoistatistik Anabilim Dalı, Çorum, Türkiye ORCID: 0000-0002-3834-3864 \\ 3 Hitit Üniversitesi, Sungurlu Meslek Yüksekokulu, Bilgisayar Teknolojileri Bölümü, Çorum, Türkiye ORCID: 0000-0002-8314-9585 \\ 4 Hitit Üniversitesi, Tıp Fakültesi, Deri ve Zührevi Hastalıklar Anabilim Dall, Çorum, Türkiye ORCID: 0000-0001-8098-1686
}

Geliş: 14.11.2018; Revizyon: 07.03.2019; Kabul Tarihi: 18.03.2019

$\ddot{0} \mathbf{z}$

Amaç: Bu çalışmada, Deri ve Zührevi Hastalıklar Anabilim Dalı Kliniğinde teledermatolog dermatoloji uzmanı tarafından konulan deri tümörü tanıları histopatolojik tanılarla karşılaştırılarak teletıp tekniğinin plastik cerrahi alanındaki başarısının test edilmesi amaçlanmıştır.

Yöntemler: Araştırmada, Hitit Üniversitesi Tıp Fakültesi, Plastik Rekonstrüktif ve Estetik Cerrahi Kliniğinde, 100 deri tümörü hastasının preoperatif lezyon fotoğrafları çekilerek bu çalışma için özel olarak tasarlanmış internet sitesine ve programa yüklendi. Elde edilen veriler bir teledermatolog dermatoloji uzmanı tarafından değerlendirildi. Daha sonra bu tanılar histopatolojik tanılarla karşılaştırılarak teletıp tekniğinin plastik cerrahide ki başarısı Cohen Kappa uyum istatistiği kullanılarak araştırıldı.

Bulgular: Analiz sonuçlarına göre kappa istatistiği $0,89(0,82-0,96)(p<0,001)$ olarak bulunmuştur. Ayrıca seboreik keratoz, aktinik keratoz, sebase hiperplazi, melanositik nevus ve kaposi sarkom için tanı doğruluğunun \%100, diğer tanılarda ise \%100' e yakın olduğu görülmektedir.

Sonuç: Literatürde teletıp kullanılarak preoperatif tanıların konulmasını araştıran telecerrahi alanında multidisipliner sınırlı sayıda çalışma bulunmaktadır. Deri tümörlerinin cerrahisinde, telecerrahi, cerrahi öncesi hastalara tanı koymada güvenilir bir yöntem olarak saptandı.

Anahtar kelimeler: Teletıp; teledermatoloji; telecerrahi; multidisipliner yaklaşım

\section{DOI: $10.5798 /$ dicletip}

Yazışma Adresi / Correspondence: Ümran Muslu, Hitit Üniversitesi, Tıp Fakültesi, Plastik Rekonstrüktif ve Estetik Cerrahi Anabilim Dalı, Çorum, Türkiye, e-mail: umrandr@hotmail.com 


\title{
A Multidisciplinary Telemedicine Application: Comparison of Preoperative Telesurgery Diagnoses with Histopathology
}

\begin{abstract}
Objective: In this study, it was aimed to test the success of telemedicine technique in the field of plastic surgery by comparing lesion diagnoses made by a teledermatologist in the Department of Dermatology with histopathologic diagnoses.

Methods: In this study, 100 preliminary pictures of skin tumor patients were taken in Hitit University Faculty of Medicine, Plastic Reconstructive and Aesthetic Surgery Clinic, and a web site and program were specially designed for this study. The obtained data were evaluated by a teledermatologist. Later, these diagnoses were compared with histopathological diagnoses and the success of the telemedicine technique in plastic surgery was investigated using Cohen Kappa statistics.

Results: According to the analysis results kappa statistic was found as $0.89(0.82-0.96)(p<0.001)$. In addition, the diagnostic accuracy for seborrheic keratosis, actinic keratosis, sebase hyperplasia, melanocytic nevus, and kaposi sarcoma was found to be $100 \%$ and close to $100 \%$ in other diagnoses.

Conclusion: There is limited number of studies investigating the contribution of preoperative telemedicine application to the surgery of skin tumors in the literature. We found that telesurgery was a reliable technique in the preoperative assessment of skin tumors.
\end{abstract}

Keywords: Telemedicine; teledermatology; telesurgery; multidisciplinary approach.

\section{GíRiş}

Teletıp, bilişim teknolojileri kullanarak tıbbi bilgi ve hizmetlerin iletilmesi ve ya uygulanmasıdır. Telecerrahi, geleneksel yüz yüze hasta muayenesi olmadan, özellikle uzak mesafedeki hastaların klinik bilgilerinin, dijital fotoğraf ve ya videolarının değerlendirilmesi yoluyla tanı konulması ve mümkün olduğunda tedavi kararı verilmesine imkan sağlayan yeni bir teknolojidir.

İki temel telecerrahi tekniği mevcuttur ${ }^{1-2}$.

a) Depola ve gönder (Store and forward)

b) Gerçek zamanlı (Real-time)

Her iki yöntemin de birbirine göre avantaj ve dezavantajları vardır. Depola ve gönder tekniğinde, telecerrahi uygulama alanındaki plastik cerrah tarafından danışılacak hastanın fotoğrafı çekilerek resimler (imajların) depolanır ve telecerrahi uzmanlık merkezine aktarılır. Konsültasyon ve uzmanlık merkezi arasında eşzamanlı hareket etme zorunluluğu yoktur. Bu yöntemi kullanan personel, bilgisayar teknolojisi hakkında yeterli birikime sahip değilse eğitim alması zorunludur. Video konferans yönteminden daha kolay ve daha az maliyetli bir tekniktir. Çalışmamız, depola ve gönder yöntemi kullanılarak gerçekleştirilmiş bir telecerrahi çalışmasıdır. Hitit Üniversitesi Tıp Fakültesi, Plastik, Rekonstrüktif ve Estetik Cerrahi Kliniğinde, 100 deri tümörü hastası preoperatif fotoğrafları çekildi; hasta bilgileri ve fotoğraflar bu çalışma için özel olarak tasarlanmış internet sitesine ve programa yüklendi ve Deri ve Zührevi Hastalıklar Anabilim Dalı Kliniğinde teledermatolog dermatoloji uzmanı tarafından bütün hastalar değerlendirildi. Daha sonra telecerrahi tanıları histopatolojik tanılarla karşılaştırılarak teletıp tekniğinin plastik cerrahide ki başarısı istatistiksel olarak araştırıldı.

Plastik Cerrahi kliniğine başvuran ardışık 100 deri tümörü hastası, cinsiyet, yaş, rrk ve meslek farkı olmadan çalışmaya dâhil edildi. Uzaktan tanı koyan teledermatoloğa öncelikle randomize olarak hasta bilgileri ve klinik fotoğraflar gönderildi. Retrospektif olarak 
değerlendirme yapıp, tanı koyması istendi. Çalışmada telecerrah ve teledermatolog görüntüleme cihazı olarak bilgisayar kullandılar.

Telecerrahide çekilen fotoğraflar ve hasta bilgileri değerlendirilerek teledermatolog tarafindan tanı konuldu ve bu tanılar daha sonra histopatolojik tanılar ile istatistiksel olarak karşılaştırıldı. Hastalara çalışma nedeniyle hiçbir özel test, tetkik veya girişimde bulunulmadı. Hastaların kimlik bilgileri saklanmadı. Demografik ve hastalık/lezyon bilgileri ve resimleri sadece ilgili teledermatoloğun ve telecerrahın erişimine açlldı. Araştırma süresince Teledermatolog ve telecerrah hasta bilgi ve resimlerinin bulunduğu siteye şifre ile erişim sağladı. Sadece bu çalışmada kullanılmak üzere özel erişimli www.telecerrahi.com alan adıyla internet sitesi kurulmuştur.

Literatürdeki daha önce yapılan çalışmalarda teledermatolojinin tanı ve tedavi etkinliğini arttırdığı bulunmuştur ${ }^{3,4}$. Multidisipliner olarak telecerrahinin teledermatolojik araçlarının/cihazlarının teledermatoloji uygulamalarının preoperatif tanıların konulmasına katkısını araştıran literatürde sınırlı sayıda çalışma bulunmaktadır. Preoperatif tanıların konulması ve bu strateji ile yapılacak cerrahinin radikal tedavi olması açısından önem arz etmektedir. Histopatolojik uyumun istatistiksel olarak anlamlı olması, gelişmiş ve pahalı sistemlerden ziyade basit teledermatoskopi sistemlerinin dermatoloji uzmanı olmayan sahalarda hem telecerrahın önünü açacak hem de histopatolojik sonuca uygun cerrahi uygulayabilmenin önünü açabilecektir. Gelişmiş ama pahalı sistemlerin basit ve uygun fiyatlı sistemlerle aynı istatistiksel uyum göstermesi, günlük pratikte teledermatolojik uygulamaların maliyetlerini de düşürebilecektir.

Çalışmamızın amacı deri tümörü ön tanısı ile plastik cerrahide değerlendirilen 100 hastanın telecerrahi yöntemi ile dermatoloji uzmanı tarafından değerlendirilmesi ve preoperatif teletıp tanılarının altın standart olan histopatolojik tanılar ile karşılaştırılmasıdır.

\section{YÖNTEMLER}

Hitit Üniversitesi Tıp Fakültesi, Plastik Rekonstrüktif ve Estetik Cerrahi Kliniğinde, ardıșık 100 deri tümörü hastasının preoperatif fotoğrafları çekildi. Hastaların hastalık bilgileri ve fotoğrafları bu çalışma için özel olarak tasarlanmış web sitesine yüklendi. Web sitesi alt yapısını PHP web programlama dili ve MYSQL veri tabanı programı oluşturmaktaydı. Deri ve Zührevi Hastalıklar Anabilim Dalı Kliniğinde konusunda uzman bir teledermatolog tarafindan hastalar değerlendirildi. Daha sonra bu tanılar histopatolojik tanılarla karşılaştırılarak teletıp tekniğinin plastik cerrahideki başarısı istatistiksel olarak araştırıldı. Araştırmamız kapsamında fotoğraflanan deri tümörlerine ilişkin sırasıyla klinik (sol) ve dermatoskopik (sağ) görüntülerden bazı örnekler Şekil 1' de gösterilmiştir.

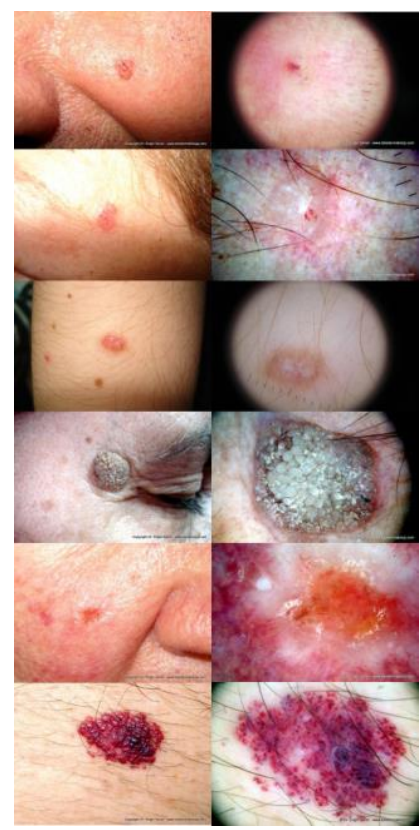

Şekil 1. Aktinik Keratoz, Bazal Hücreli, Dermatofibrom, Seboreik Keratoz, Skuamöz hücreli karsinom, Vasküler tümör 


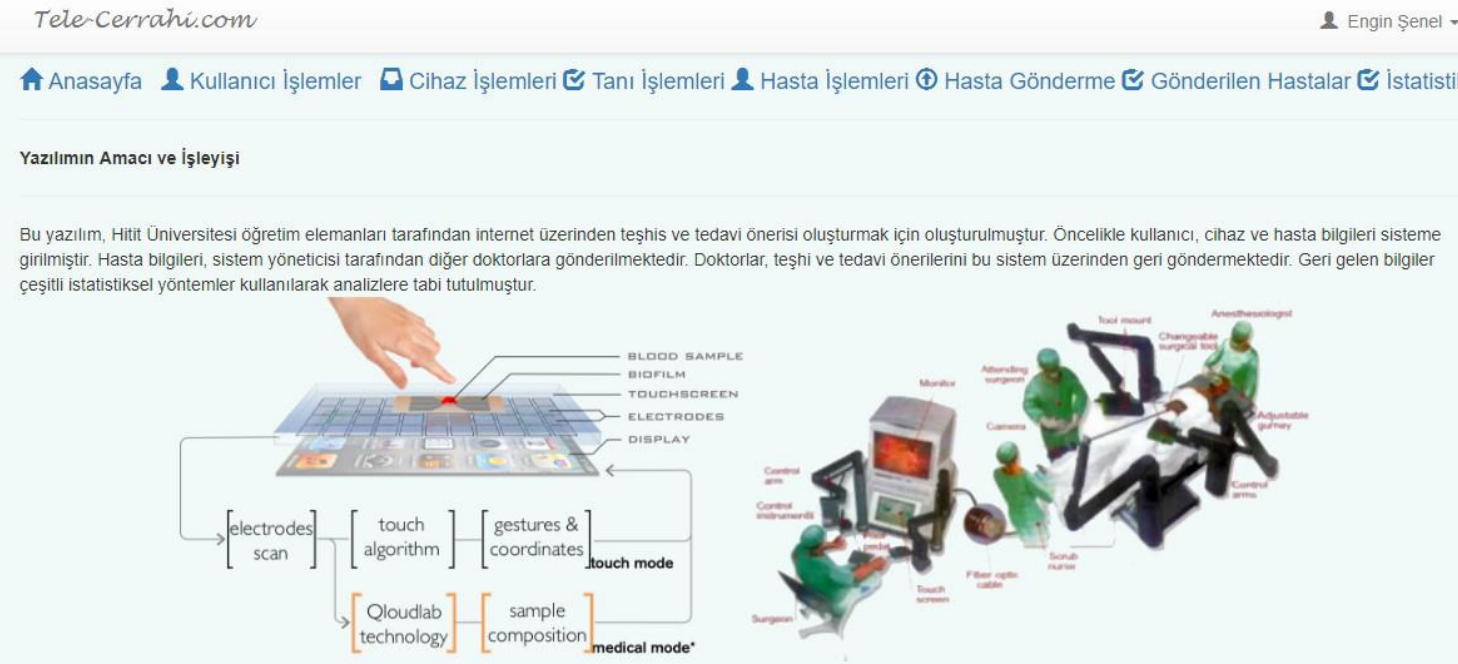

Şekil 2. Yönetici Ana sayfası

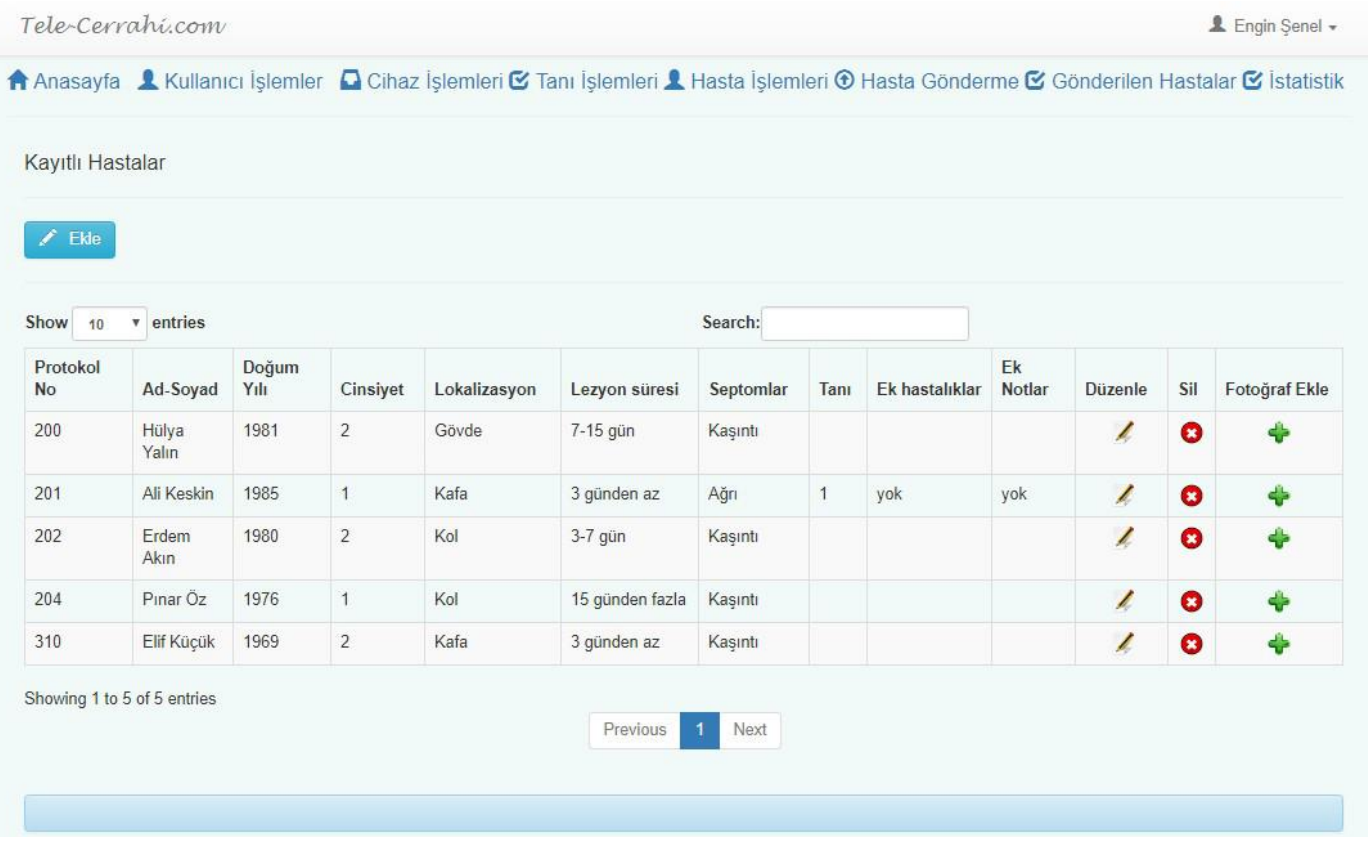

Şekil 3. Kullanıcılar, Cihazlar, Tanılar ve Hastalar

\section{Internet sitesi ve yazılımın oluşturulması}

Hasta resimlerinin ve bilgilerinin depolanması için www.telecerrahi.com alan adı ve site dosyalarının barındırılacağı hosting alınmıştır. Yazılım PHP web programlama dili ve MYSQL veri tabanı kullanılarak nesne tabanlı olarak kodlanmıştır. İnternet sitesine yüklenen yazılım modüler bir yapıya sahiptir ve yönetici tarafı şu menülerden oluşur:

- Kullanıcilar Ara yüzü

- Cihazlar Sekmesi

- Tanı Birimi

- Hastalar Bölümü

- Hasta gönderme ünitesi

- İstatistik Analiz Alanı 
A

Tele-Cerrahicom

2 Engin Șenel

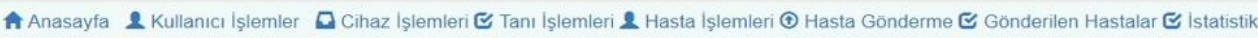

Hastayı Doktora Gonder

Tanı

Cinsiyet

Fotoğraf Turü

1-Klinik

3-Dermatoskop (DermLite DL1)

2-Dermatoskop (Dermlite Cam)

4-Dijital mikroskop (Celestron)

5-Dijital mikroskop (Dinolite VGA

6-Dijital mikroskop (Dinolite 1.3 M)

7-Diital mikroskop (Dinolite $5 \mathrm{M}$ )

Q Listele

B

\begin{tabular}{|c|c|c|c|c|c|c|c|}
\hline \multicolumn{8}{|l|}{ Umran Muslu } \\
\hline - Tümünü Seç & Hasta ID & Fotoğraf ID & Ad-soyad & Cinsiyet & Doğum Tarihi & Cihaz & Fotoğraf \\
\hline 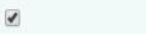 & 200 & 169 & Hülya Yalın & 2 & 1981 & 1 & 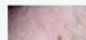 \\
\hline$\checkmark$ & 201 & 167 & Ali Keskin & 1 & 1985 & 1 & \\
\hline
\end{tabular}

KAYDET

Şekil 4. Hasta Gönderme (A), Hasta Gönderme (B)

Telecerrahicom

e Engin Șenel .

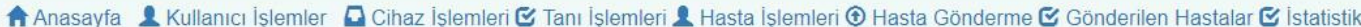
Değerlendirilen Hastalar

\begin{tabular}{|c|c|c|c|c|c|c|c|c|c|c|c|c|}
\hline Protokol No & Adı & Doğum Tarihi & Cinsiyet & Lokalizayon & Lezyon süresi & Semptom & Tanı & Diğer Hastalıklar & Ek notlar & Doktor Id & Tele-Tanı & Tele-Tedavi \\
\hline 201 & Ali Keskin & 1985 & 1 & Kafa & 3 günden az & Ağrn & 5 & Șeker & yok & 37 & 1 & 1 \\
\hline 200 & Hülya Yalin & 1981 & 2 & Gövde & $7-15$ gün & Kașintı & 2 & & & 29 & 2 & 2 \\
\hline 200 & Hülya Yalın & 1981 & 2 & Gövde & $7-15$ gün & Kașıntı & 2 & & & 37 & 7 & 3 \\
\hline 310 & Elif Kücük & 1969 & 2 & Kafa & 3 günden az & Kașıntı & 1 & Tansiyon & Yok & 37 & 5 & 2 \\
\hline
\end{tabular}

Şekil 5. İstatistik Analiz Alanı 


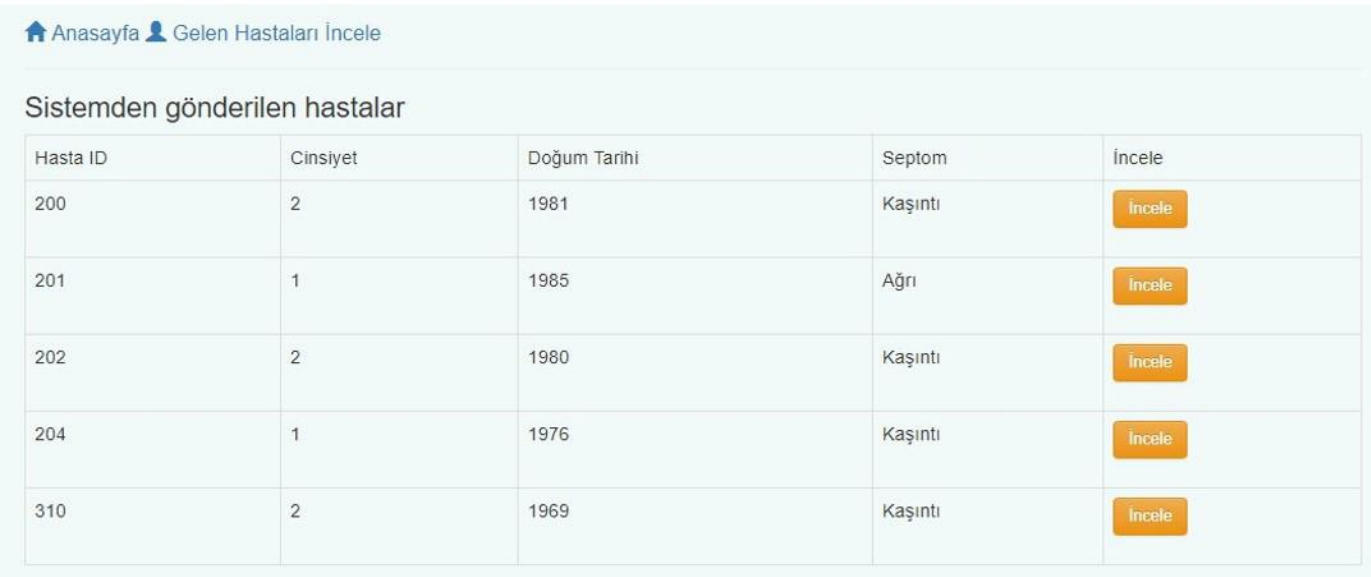

B
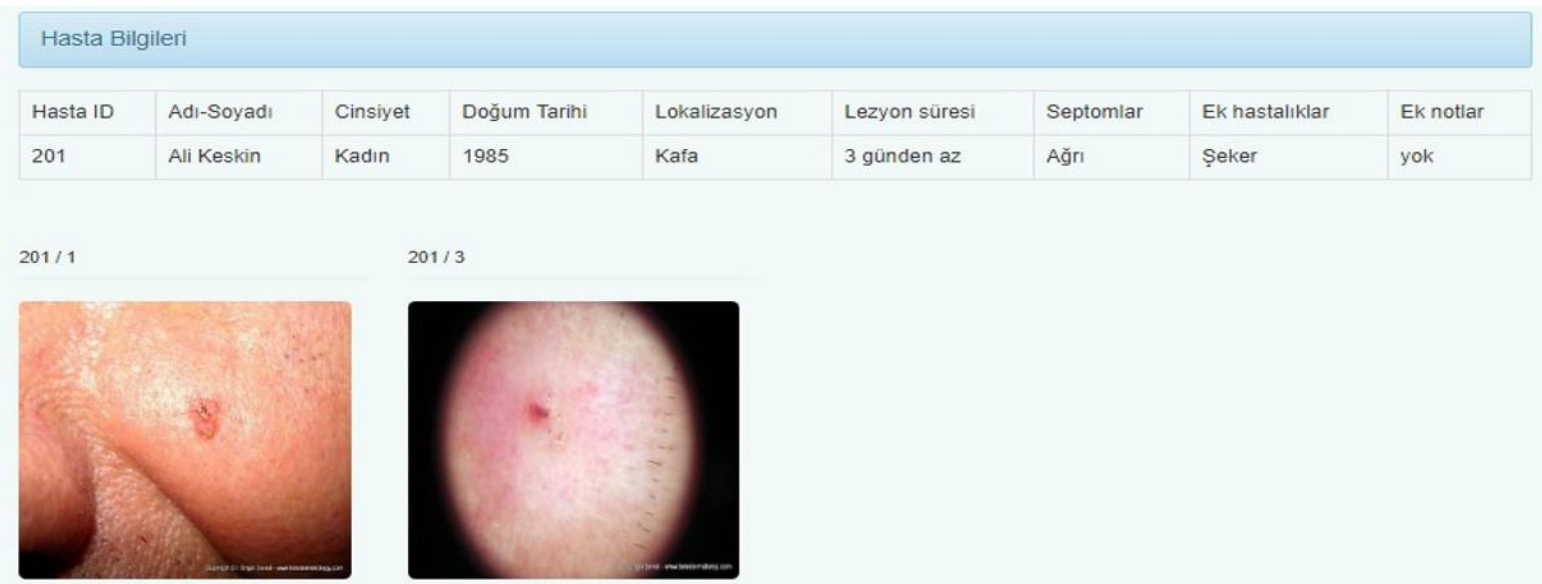

$201 / 3$

Tanı seciniz

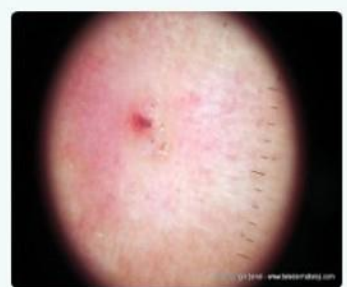

$\checkmark$

Tedaviseçiniz

Şekil 6. Doktora Gelen Hastalar (A), Doktora Gelen Hastaların Incelenmesi (B)

Yönetici kısmında, hastaları inceleyecek olan doktorlar sisteme kullanıcı olarak dahil edilmektedir. Cihazlar sekmesinde klinikte kullanılan farklı özellikte ve kalitede görüntü alma özelliğine sahip cihazlar eklenmektedir. Tanı biriminde hasta tanıları eklenmekte ve düzenlenmektedir. Hasta bilgileri hastalar bölümünde eklenmekte ayrıca bu kısımda farklı cihazlarla çekilen görüntüler ilgili hasta alanına eklenmektedir. Hasta gönderme ünitesi sayesinde sisteme kayıtlı doktorlara farklı sayıda cihaz görüntüsüne sahip hastalar incelenmesi için gönderilmektedir. İstatistik kısmında ise doktorlar tarafından incelenen hastaların ve teletanı, teletedavi önerileri listelenmektedir. Bu kısımda ayrıca sisteme ait genel bilgiler; doktor sayısı, hasta sayısı, doktorlara gönderilen hasta sayısı ve bu hastaların kaç tanesinin incelendiği bilgileri yer almaktadır.

Kullanıcı tarafında ise hasta listeleme ve inceleme menüsü mevcuttur. İnceleme modülünde hastalara ait bilgiler ve görüntüler doktorun ekranına düşmektedir. Doktor gerekli tanı ve tedavi önerisini kaydettiği anda istatistik kısmına sonuçlar ulaşmaktadır. Tasarlanan sistem aşağıda eklenen şekiller ve açıklamaları ile tanımlanmıştır (Şekil 2-6). 
Sisteme giriş yapıldıktan sonra yönetici ve doktor yetkisindeki kullanıcılar için farklı kullanıcı ara yüzleri açılmaktadır.

\section{Yönetici Ekranları}

$\mathrm{Bu}$ kısımda yönetici yetkisi ile giriş yapan kullanıcı ekranlarına yer verilmiştir. Şekil 2'de web tabanl teşhis ve tedavi önerisi sunan sistemin yönetici ara yüzü yer almaktadır. Yöneticiler kullanıcı, cihaz, tanı ekleme ve hasta kayıt yetkinlerine sahiptir. Ayrıca, kayıtlı hastaları incelenmesi için doktorlara gönderebilmektedir. İstatistik menüsü altında sistemi işleyişiyle ilgili özet bilgiler yer almaktadır. Şekil 3'te yöneticilerin kullanıcıları, cihazları, tanıları ve hastaları ekleme, listeleme, silme ve düzenleme, yapabildiği ekran görüntüsü yer almaktadır. Şekil 4 (A)'da yöneticilerin hastaları doktorlara gönderdiği ekran görüntüsü yer almaktadır. Hastalar tanı, cinsiyet ve fotoğraf türü gibi çeşitli filtreler kullanılarak istenilen doktora gönderilebilmektedir. Şekil 4 (B)'de yöneticilerin hasta gönderme așamasında filtre uygulayarak listelediği görülmektedir. $\mathrm{Bu}$ aşamadan sonra yönetici dilediği sayıda hastayı doktorlara gönderebilmektedir. Şekil 5'te yöneticiler doktorlara gönderdiği hastalarla ilgili özet bilgiler inceleyebilmektedir.

\section{Kullanıcı Ekranları}

$\mathrm{Bu}$ kısımda normal kullanıcı yetkisi ile giriş yapan kullanıcı ekranlarına yer verilmiştir. Şekil 6 (A)'da doktorların gelen hasta özet bilgilerini gördügü ve isterse inceleyebildiği kısım görülmektedir. Şekil 6 (B)'de doktorların lezyon fotoğraflarını inceleyebildiği, tanı ve teşhis belirleyerek sisteme kaydettiği kısım görülmektedir.

Hitit Üniversitesi Tıp Fakültesi, Plastik Rekonstrüktif ve Estetik Cerrahi Kliniğinde, 100 ardışık deri tümörü hastasının preoperatif fotoğrafları çekilerek bu çalışma için özel olarak tasarlanmış internet sitesine ve programa yüklenmiş. Deri ve Zührevi
Hastalıklar Anabilim Dalı Kliniğinde konusunda uzman bir teledermatolog tarafindan hastalar değerlendirilmiştir. Daha sonra bu tanılar histopatolojik tanılarla karşılaştırılarak teletıp tekniğinin plastik cerrahideki başarısı istatistiksel olarak araştırılmıștır. Çalışmamız için Hitit Üniversitesi Etik Kurul biriminden onay alındı (2017/12) ve çalışma Helsinki Bildirisine uygun șekilde yürütüldü.

\section{İstatistiksel Yöntem}

Araştırmamızda veri analizleri için SPSS (Version 22.0, SPSS Inc., Chicago, IL, USA; lisans, Hitit Üniversitesi) paket programı kullanıldı. Tanımlayıcı istatistikler kategorik veriler için sayı ve yüzde olarak sunuldu. Tanılar arasında istatistiksel anlamlı farklılık olup olmadığı Mc Nemar -Bowker test ile belirlendi ${ }^{5}$. Tanı testi sonuçları kategorik yapıda olduğu durumda kullanılan uyum katsayılarından birisi Cohen Kappa istatistiğidir. Araştırmada, eşit sayıda kategorisi olan tanı testinin kullanıldığı durumlarda iki değerlendirici arasındaki uyumu ölçmek için kappa istatistiği kullanılmıştır. İstatistiki anlamlılık düzeyi için $\mathrm{p}<0,05$ olarak değerlendirilmiştir. Literatürde Kappa istatistiğinin 0,40 ile 0,60 arasında olması orta derecede uyuşma, 0,61 ile 0,80 arasında olması önemli derecede uyuşma olması anlamına, 0,80 ile 1,00 arasında olması ise neredeyse mükemmel uyuşma olması anlamina gelmektedir.

\section{BULGULAR}

Araştırmaya 48 (\%48) erkek ve 52 kadın (\%52) olmak üzere toplam 100 hasta alınmıştır. Hastaların yaş ortalaması 52,8 \pm 13,3 yaş olarak bulundu. Hastaların hiçbirinde önceden kanser öyküsü yoktu. Verilerin değerlendirilmesi sonucu öncelikle deri tümörleri tanı sonuçları için tanımlayıcı istatistikler Tablo 1'de sunulmuştur. Tablo 1 incelendiğinde en yaygın tanının bazal hücreli karsinom (\%36) olduğu görülecektir. Bunu dermatofibrom (\%13) ve keratoakantom (\%12) takip etmiştir (Tablo 1). 
Tablo 1: Standart değerlendirme tanı sıklık ve yüzdeleri

\begin{tabular}{|lc|}
\hline & Sıklık \\
\hline Seboreik keratoz & 2 \\
Aktinik keratoz & 7 \\
Dermatofibrom & 13 \\
Sebase hiperplazi & 4 \\
Skuamöz hücreli karsinom & 11 \\
Bazal hücreli karsinom & 36 \\
Melanositik nevüs & 4 \\
Keratoakantom & 12 \\
Kaposi sarkom & 2 \\
Vasküler tümörler & 9 \\
Toplam & $\mathbf{1 0 0}$ \\
\hline
\end{tabular}

Araştırmada 1. Gruptaki teledermatoloji uzmanına sadece lezyonların klinik ve dermatoskopik görüntüleri ve standart bilgileri verilmiş ve tanı koyması istenmiştir. Daha sonra teledermatoloğun koyduğu tanılar ile histopatolojik tanılar arasındaki uyum derecesi kappa istatistiği ile Tablo 2'de sunulmuştur. Teledermatolog ile histopatoloji sonuçları arasında istatistiksel olarak anlamlı fark yok idi

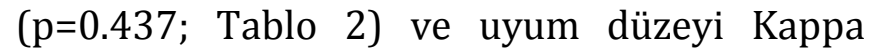
istatistiğine göre ( $\kappa=0.89(0.82-0.96))$ yüksek düzeyde uyumlu olarak bulundu.

Tablo 2: Tanı güvenirliği Kappa uyum değerleri

\begin{tabular}{|c|c|c|c|}
\hline \multicolumn{4}{|c|}{ Histopatoloji } \\
\hline & Kарра (к) & & $\begin{array}{c}\text { Mc Nemar- } \\
\text { Bowker }\end{array}$ \\
\hline Teledermatolog & $0,89(0,82-0,96)$ & $P<0,001$ & $P=0,437$ \\
\hline
\end{tabular}

Tanıların lezyonlara göre dağılımı ise Tablo 3'te sunulmuştur. Satırda verilen tanılar teledermatoloğun tanıları, sütunda verilen tanılar Altın standart histopatoloji tanılarıdır. Tablonun köşegenindeki sayılar doğru tanı sayılarını göstermektedir.

\section{TARTIŞMA}

Histopatolojik uyumun istatistiksel olarak anlamlı bulunması, gelişmiş ve pahalı sistemlerden ziyade basit teledermatoskopi sistemlerinin dermatoloji uzmanı olmayan sahalarda hem telecerrahinin hem de histopatolojik sonuca uygun cerrahi uygulamasının önünü açabilecektir.

Ferrandiz ve ark.'nın 2007 yllında 134 melanositik olmayan deri tümörü hastalarında yaptığı benzer bir telecerrahi çalışmasında telecerrahinin uyumu $\kappa=0.86$ olarak saptanmıştır ${ }^{6}$ Bizim çalışmamızda teledermatoloğun uyguladığı telecerrahi tekniğinin uyumu $\kappa=0.89$ (0.82-0.96) olarak bulundu. Sonuçta iki çalışmada da telecerrahi uyumu "mükemmel" olarak saptanmıştır.

Janda ve ark.'nın 2019 yılında yaptığı çalışmada pratisyen hekimlerin teledermatoloji uygulanmasındaki memnuniyetini araştırmış ve gelişen teknoloji ile ortaya çıkan telesağlık hizmetlerinde daha rahat karar vermek için yeni uygulama modelleriyle ilerlemenin önemli olduğu belirtilmiştir ${ }^{7}$. Mehrtens ve arkadaşları 2019 yılında yaptıkları çalışmada geriye dönük olarak elektronik hasta veri tabanından çektikleri 25555 hastanın tanısal dağılımını belirlemişlerdi. Toplamda, 14 yıllık veri kaydının taranması sonucunda vakalarda en sık görülen lezyonların benign melanositik nevüs (\%25), seboreik keratoz (\%22) ve bazal hücreli karsinom (\%19) olduğunu raporlamışlardır ${ }^{8}$. 
Tablo 3: Tanıların lezyonlara göre dağılımları

\begin{tabular}{|c|c|c|c|c|c|c|c|c|c|c|}
\hline & 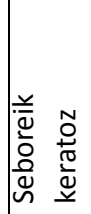 & 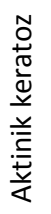 & 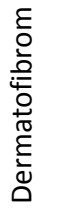 & 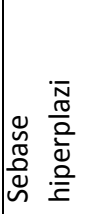 & 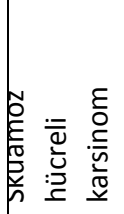 & 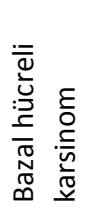 & 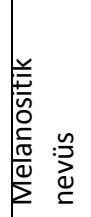 & 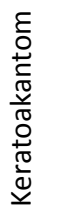 & 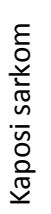 & 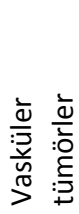 \\
\hline Seboreik keratoz & 2 & & & & & & & & & \\
\hline Aktinik keratoz & & 7 & & & & & & & & \\
\hline Dermatofibrom & & & 12 & 1 & & & & & & \\
\hline Sebase hiperplazi & & & & 4 & & & & & & \\
\hline Skuamöz hücreli karsinom & & & 1 & & 10 & & & & & \\
\hline Bazal hücreli karsinom & & & 1 & & 1 & 32 & & 1 & & 1 \\
\hline Melanositik nevüs & & & & & & & 4 & & & \\
\hline Keratoakantom & & 1 & & & 1 & & & 10 & & \\
\hline Kaposi sarkom & & & & & & & & & 2 & \\
\hline Vasküler tümörler & & & & & & & 1 & & & 8 \\
\hline
\end{tabular}

Coustasseb ve ark.'nın 2019 yılında yaptıkları çalışmada kırsal bölgede yaşayan bireylerde dermatolojik erişiminin arttırılmasının saptanmasinda teledermatolojinin kullanılmasını incelemişler. Teledermatolojinin kırsal alanlarda, dermatolojik erişimi iyileştirme noktasında çok yararlı olduğunu belirtmişlerdir.

Dermatoloğun teledermatolojiyi kullanımındaki uyumu ve isteği teknolojinin başarısını direkt etkilediğini vurgulamışlardır9.

Koch ve arkadaşları (2018) teledermatolojinin hasta güvenliğinin yanı sıra maliyeti ve sevk süresini de azalttığını belirterek teletıp aracılığıyla pratisyen hekimler ve dermatologlar arasındaki işbirliğinin arttırılabileceğini ifade etmişlerdir. Özellikle kırsal alanlardaki hastaların bu sağllk hizmeti yeniliğinden yararlanması gerektiğini vurgulamışlardır. Özellikle İngiltere, Hollanda gibi birçok Avrupa ülkesinde kullanılan teledermatolojinin Almanya da henüz rutin olarak uygulanmadığını belirtmişlerdir. Yapılan çalışmada elde edilen tecrübelerle gelecekte
Alman tıbbında teledermatolojinin daha fazla uygulanmasının önemini belirtmișlerdir ${ }^{10}$.

Zheng (2018) ise çalışmasında Çin'de gelişmemiş ve uzak coğrafi bölgelerde doğru teşhisin konulabilmesinde ve dermatologlar arasında dayanışma ve bilgi paylaşımı açısından teledermatolojinin getireceği katkılardan bahsetmiștiri11. Şenel ve ark. (2018) ise teledermatoloji yayınlarının yıl bazlı artış trendini yaptığ 1 bibliyometrik analizler ile ortaya koymuştur ${ }^{12}$.

Bizim çalışmamızda da hem tanılar arasında yüzdelere göre uyum bulunması hem de kappa istatistiğine göre tanıların yüksek düzeyde uyumlu olarak bulunması teledermatolojinin yaygın olarak kullanılabileceğini göstermiştir.

\section{SONUÇ}

En yaygın tanı bazal hücreli karsinom (\%36) olarak tespit edildi. Bunu dermatofibrom (\%13) ve keratoakantom (\%12) takip etti. Proje kapsamında geliştirilen telecerrahi sistemi ile deri tümörlerinin cerrahisinde, telecerrahi ile hastalara cerrahi öncesi konulan tanılar, cerrahi sonrası histopatoloji ile 
konuların tanılar ile \%91 uyumlu olarak bulundu. Teledermatolog ile histopatoloji sonuçları arasında istatistiksel olarak anlamlı fark yok idi ve kappa istatistiğine göre yüksek düzeyde uyum vardı. Sonuç olarak deri tümörlerinin cerrahisinde, telecerrahi, cerrahi öncesi hastalara tanı koymada güvenilir bir yöntem olarak saptandı.

Çıkar Çatışması Beyanı: Yazarlar çıkar çatışması olmadığını bildirmişlerdir.

Finansal Destek: Bu çalışma her hangi bir fon tarafından desteklenmemiştir.

Declaration of Conflicting Interests: The authors declare that they have no conflict of interest.

Financial Disclosure: No financial support was received.

\section{KAYNAKLAR}

1. Senel E. History of teledermatology: a technique of the future in dermatology. Skinmed 2010; 8: 167-70

2. Senel E, Demir E. An update and evaluation of telemedicine and teledermatology publications for 2014. Skinmed. 2016; 14: 157-8.

3. Senel E, Baba M, Durdu M. The contribution of teledermatoscopy to the diagnosis and management of non-melanocytic skin tumours. Journal of telemedicine and telecare. Jan 2013; 19: 60-3.
4. Warshaw EM, Gravely AA, Nelson DB. Accuracy of teledermatology/teledermoscopy and clinic-based dermatology for specific categories of skin neoplasms. Journal of the American Academy of Dermatology. Aug 2010; 63: 348-52.

5. Karapınar S, Uruç V, Özden R, ve ark. Rotator manşet yırtığı tamirinde mini açık yaklaşımla tek-sıra sütürankor tekniğinin klinik ve radyolojik sonuçları, Dicle Tip Dergisi, 2014; 41: 347-51.

6. Ferrandiz L, Moreno-Ramirez D, Nieto-Garcia A, et all. Teledermatology-based presurgical management for nonmelanoma skin cancer: a pilot study. Dermatologic Surgery. 2007; 33: 1092-8.

7. Janda M, Horsham C, Koh U, et all. Evaluating healthcare practitioners' views on store-and-forward teledermoscopy services for the diagnosis of skin cancer. Digital Health. 2019; 5: 1-11.

8. Mehrtens SH, Shall L, Halpern SM. A 14-year review of a UK teledermatology service: experience of over 40 000 teleconsultations. Clinical and experimental dermatology. 2019; doi:10.1111/ced.13928.

9. Coustasse A, Sarkar R, Abodunde B, et a ll. Use of Teledermatology to Improve Dermatological Access in Rural Areas. Telemedicine and e-Health. 2019; doi: 10.1089/tmj.2018.0130

10. Koch R, Polanc A, Haumann H, et all. Improving cooperation between general practitioners and dermatologists via telemedicine: study protocol of the cluster-randomized controlled TeleDerm study. Trials. 2018;19: 583.

11. Zheng Y. Lin Y, Cui Y, et all. Teledermatology in China: History, Current Status, and the Next Step. J Investig Dermatol Symp Proc. 2018; 19: 71-3.

12. Şenel E, Demir E, Artüz RF, Bibliometric Evaluation of Global Productivity of Teledermatology Publications between 1975 and 2017 with a 3-Year Update. Indian journal of dermatology. 2018; 63: 437. 